\title{
O Direito à Moradia e as contradições da Desigualdade Social
}

\section{The Right to Housing and Contradictions of Social Inequality}

\author{
Tássia A. Gervasoni ${ }^{1}$ \\ Carina Lopes de Souza ${ }^{2}$
}

\begin{abstract}
RESUMO
O presente estudo tem como tema central o direito social à moradia, propondo-se a investigar, em abordagem mais ampla, a extensão da sua proteção constitucional e, paralelamente, as dificuldades de sua efetiva implementação em um país marcado por uma desigualdade social crescente. Assim, a pesquisa questiona se e como as desigualdades sociais agravam o déficit habitacional e quais as perspectivas de enfrentamento a esse problema? Utiliza-se uma metodologia de abordagem fenomenológico-hermenêutica, métodos de procedimento histórico e monográfico, aliados à técnica de pesquisa por documentação indireta. Como resultados, destaca-se que as insuficiências com relação à prestação do direito à moradia no Brasil vão muito além da falta de habitações, de modo que as políticas necessárias à reversão do déficit habitacional precisam urgentemente considerar outros aspectos, notadamente a redução da desigualdade social e a proteção de um direito à cidade.
\end{abstract}

\section{PALAVRAS-CHAVE:}

Direitos sociais, direito à moradia, desigualdade social, direito à cidade.

\begin{abstract}
The present study has as central theme the social right to housing, proposing to investigate, in a broader approach, the extension of its constitutional protection and, in parallel, the difficulties of its effective implementation in a country marked by social inequality growing. So, the research questions if and how social inequalities aggravate the housing deficit and what are the prospects of coping with this problem? We use the approach methodology of phenomenological-hermeneutical, methods of procedure historical and monographic, allied to the technique of research by indirect documentation. As a result, it should be noted that the shortcomings with regard to the provision of the right to housing in Brazil go well beyond the lack of housing, so that the policies necessary to reverse the housing deficit urgently need to consider other aspects, notably the reduction of social inequality and the protection of the right to the city.
\end{abstract}

KEYWORDS:

Social rights, right to housing, social inequality, right to the city.

\footnotetext{
1 Doutora em Direito pela Universidade do Vale do Rio dos Sinos, com período sanduíche na Universidad de Sevilla (Espanha). Mestre e Graduada em Direito pela Universidade de Santa Cruz do Sul. Professora na Faculdade Meridional - IMED. Professora Colaborada do PPGD - Mestrado na IMED. Pesquisadora do Grupo de Pesquisa Estado e Constituição, vinculado ao CNPq. Advogada.

${ }^{2}$ Acadêmica no $10^{\circ}$ de Direito na Faculdade Meridional - IMED.
} 


\section{INTRODUÇÃO}

O direito social à moradia, a despeito de previsões pontuais em textos legais e algumas aproximações com outros direitos fundamenteis, somente foi expressamente incluído na Constituição Federal no ano de 2000, com a Emenda Constitucional no 26 . Trata-se, portanto, de uma previsão bastante recente, que embora reflita um problema social bastante complexo e latente no Brasil, ainda carece de mais detalhados e aprofundados estudos, sobretudo que possam trazer alguma contribuição para a sua implementação.

Visando somar à missão de contribuir para uma adequada prestação do direito à moradia, este estudo propõe-se a investigar, em abordagem mais ampla, a extensão da sua proteção constitucional e, paralelamente, mapear algumas dificuldades de sua efetiva implementação. Dentre essas dificuldades, trabalha-se como a hipótese de uma estreita vinculação entre o direito fundamental em questão e a desigualdade social crescente no país.

Assim, a pesquisa questiona se e como as desigualdades sociais agravam o déficit habitacional e quais as perspectivas de enfrentamento a esse problema? Para tanto, o trabalho será divido em três momentos: (i) inicialmente, será feita uma retomada acerca do desenvolvimento histórico dos direitos sociais e a consolidação dos instrumentos jurídicos protetivos do direito à moradia, visando demonstrar as resistências que de longa data acompanham tal direito; (ii) em seguida, proceder-se-á uma investigação sobre a complexidade conceitual do direito fundamental social à moradia, buscando esclarecer as definições materiais desse direito e como se distingue e se relaciona com outras garantias; (iii) por fim, pretende-se apontar e avaliar as necessidades habitacionais no Brasil e as relações contraditórias estabelecidas pelo quadro de desigualdade social crescente.

Considerando o problema e estrutura de investigação propostos, utiliza-se uma metodologia de abordagem fenomenológico-hermenêutica (analisando os objetos de estudo desde a sua inserção no mundo, no seu "como"), métodos de procedimento histórico (ponderando as influências e impactos do passado na conformação do presente) e monográfico (mantendo um objeto de análise bem delimitado), aliados à técnica de pesquisa por documentação indireta. 


\section{O DESENVOLVIMENTO HISTÓRICO DOS DIREITOS SOCIAIS E A CONSOLIDAÇÃO DE INSTRUMENTOS JURÍDICOS DE PROTEÇÃO AO DIREITO À MORADIA}

O século XX revelou um cenário de grandes lutas políticas, nesse momento histórico, os direitos sociais alcançam evidência, sobretudo a partir da Revolução Russa de 1918. A Rússia rompeu os limites jurídicos do Estado de Direito e do modelo constitucional ocidental, apresentando uma Declaração de Direitos - Declaração dos direitos do povo trabalhador e explorado - e uma Constituição repletas de inovações (NOVAIS, 2010).

Notadamente a Revolução Russa apresentou uma nova compreensão acerca dos direitos fundamentais, afastando-os da concepção de direitos contra o Estado assentes na autonomia individual. Instituiu, assim, um programa de funcionalização integral do exercício dos direitos fundamentais voltado à consolidação do regime político e poder estatal vigente (NOVAIS, 2010). Não haveria aqui direitos contra o Estado, uma vez que este pertenceria inteiramente à classe proletária, diferente da lógica burguesa que entendia os direitos fundamentais como garantias jurídicas.

Essa funcionalização estatal dos direitos conferiu aos trabalhadores, antes às margens da sociedade, direitos realizáveis não contra o Estado, mas através do Estado. Mais precisamente, emerge um novo modelo estatal empenhado na realização de uma sociedade superior, um Estado que se encontra nas mãos dos titulares dos direitos sociais. Observou-se assim uma contraposição entre os dois modelos de organização do Estado. Uma organização estatal demarcada pela expressividade dos diretos sociais e o Estado burguês, delineado pelos tradicionais direitos de liberdade (NOVAIS, 2010).

Muito embora a postura anti-individualista e anti-liberal orientadora da contraposição entre os direitos sociais e os direitos de liberdades tenha emergido do regime soviético, não permaneceu adstrita a ele (NOVAIS, 2010). Nas décadas seguintes, a defesa dos direitos sociais foi assumida, ainda que com perspectivas e fundamentos diversos, por outros regimes autocráticos conservadores. A Constituição portuguesa de 1933, a exemplo disso, conferiu aos 
direitos sociais destaque até então inexistente nas demais constituições do Estado de Direito Liberal (NOVAIS, 2010).

A defesa dos direitos sociais não se encerrou a partir da elaboração de textos constitucionais, sequer encontrou aí morada acolhedora que lhe permitisse atravessar o conturbado século XX (NOVAIS, 2010), prosseguindo, assim, como temática central de discussão do Estado Constitucional do século XXI. Necessário registrar que a principal e mais contundente defesa dos direitos sociais foi realizada pelo Estado Social e Democrático de Direito, em uma visão complementar e integrada com a manutenção dos direitos de autonomia individual.

Surgem, então, as primeiras constituições do Estado de Direito Social, como por exemplo a Constituição Mexicana de 1917 e a Constituição de Weimar de 1919, cujos textos assumiram o desafio de abrigar tanto os direitos sociais como os direitos de liberdades. Tais documentos constitucionais contribuíram de forma significativa para a consolidação desse novo modelo de Estado - o Estado Social de Direito. Assim, passa-se a exigir, não a abstenção ou a mera presença do Estado para garantir a liberdade e a propriedade de alguns, mas sim um comportamento ativo que assegure aos indivíduos o usufruto de seus direitos (LEDUR, 2009, p. 74). Consequência dessa nova concepção é o amplo reconhecimento dos direitos sociais.

Em que pese a Declaração dos Direitos do Homem e do Cidadão da Revolução Francesa desde 1789 proclamasse que a Constituição se traduzia nos direitos fundamentais e na separação de poderes, por mais de meio século esses direitos permaneceram no limbo da mera proclamação política simbólica (NOVAIS, 2010). Não havia, portanto, qualquer distinção entre os direitos de liberdades e os direitos sociais, pois representariam aquilo que o legislador democrático livremente decidisse. A diferença de natureza ou relevância jurídica entre esses dois tipos de direitos não era, naquele momento, dogmaticamente interessante (NOVAIS, 2010).

Em todo caso, importa consignar que a defesa dos direitos sociais alargou-se extraordinariamente, confluindo em uma série de movimentos socialistas e sociais-democratas (NOVAIS, 2010). Inegável que a defesa dos direitos sociais tem um forte cunho político. No plano do direito internacional, a exemplo disso, observou-se o alinhamento político de 
diferentes Estados nas discussões propostas na ONU acerca da consolidação dos direitos sociais na Declaração Universal dos Direitos do Homem.

Essa participação política torna-se natural e compreensível uma vez que os direitos sociais demandam do Estado prestações fáticas de natureza econômica e social. Assim, surgem questionamentos ligados ao papel desempenhado pelo Estado, especialmente no que diz respeito à promoção do bem-estar social e seu posicionamento frente à autonomia individual (NOVAIS, 2010).

Como retratado até então, os direitos sociais emergiram da denominada segunda dimensão de direitos, no final do século XIX, alcançando reconhecimento no cenário internacional a partir dos movimentos constitucionalistas do século $\mathrm{XX}$, que buscaram consagrá-los em um número significativo de constituições (SARLET; MARINONI; MITIDIERO, 2014). Não obstante, é necessário destacar que os direitos sociais são direitos indispensáveis à manutenção de condições dignas de existência, a exemplo disso tem-se a moradia, objeto central de análise da presente pesquisa.

Os instrumentos internacionais de proteção elaborados no século $\mathrm{XX}$ inseriram os direitos sociais na ordem jurídica mundial. Notadamente, a Declaração Universal dos Direitos Humanos (1948) conferiu-lhes maior proteção e segurança jurídica, em seu artigo XXV resguardou elementos essenciais a um padrão de vida digno, referindo-se inclusive à habitação. Embora o conteúdo jurídico da moradia transcenda o conceito de habitabilidade, a previsão normativa contida na declaração constituiu marco inicial do processo reconhecimento deste direito.

Desde então, observou-se a consolidação da moradia como direito humano universal indispensável à garantia da dignidade da pessoa humana. Os tratados internacionais elaborados após 1948 reafirmaram o compromisso dos Estados em promover e proteger este direito. O Pacto Internacional dos Direitos Econômicos, Sociais e Culturais de 1966, ratificado por cerca de 160 nações, incluindo o Brasil, enuncia um extenso catálogo de direitos, dentre os quais está a necessidade da manutenção de condições à moradia digna (PIOVESAN, 2012). O artigo 11 prevê cooperação ativa dos Estados signatários na consecução desse direito: 
moradia adequadas, assim como a uma melhoria continua de suas condições de vida. Os Estados Partes tomarão medidas apropriadas para assegurar a consecução desse direito, reconhecendo, nesse sentido, a importância essencial da cooperação internacional fundada no livre consentimento (PIEDESC, 1966).

Oportuno destacar a participação ativa da Organização das Nações Unidas - ONU na elaboração de documentos legais que conferiram maior respaldo jurídico ao processo de reconhecimento e consolidação do direito à moradia. Neste contexto, a Declaração de Vancouver sobre Assentamentos Humanos - Habitat I, realizada em 1976, promoveu políticas e estratégias de desenvolvimento de moradias alinhadas à temática da sustentabilidade. Destaca-se, ainda, a expressiva contribuição da Agenda Habitat II, em 1996, à delimitação do conteúdo e extensão deste direito. Em que pese o direito à moradia interligar-se a uma série de garantias jurídicas, a Conferência Habitat II sistematizou diretrizes conceituais indispensáveis a sua efetivação, assim como, estabeleceu procedimentos hábeis aos Estados signatários na intenção oferecer soluções a problemática dos assentamentos humanos precários (FACCHINI, 2015a).

Os documentos de caráter regional apresentaram maior timidez quanto à proteção legal de um direito à moradia. Verifica-se ter sido na Carta de Direitos Fundamentais da União Europeia em 2000 a primeira previsão expressa à moradia em âmbito regional. Em seu artigo 34 a Carta resguarda o direito a uma assistência social que assegure existência condigna aos hipossuficientes, sobretudo no que se refere às necessidades habitacionais (UNIÃO EUROPEIA, 2000).

Nessa perspectiva, observa-se ser inequívoco o reconhecimento e previsão do direito à moradia na ordem jurídica mundial. A partir do desenvolvimento de instrumentos normativos de caráter internacional e regional a moradia passou a ser objeto de maior proteção jurídica e, progressivamente, foi recepcionada pelo direito constitucional interno.

No que se refere ao direito pátrio, percebe-se que mesmo diante do reconhecimento em âmbito internacional da moradia como direito humano universal, sua positivação no ordenamento jurídico brasileiro é recente. O texto constitucional teceu referências implícitas à moradia ao disciplinar direitos correlatos. Observa-se que ao definir como competência comum da União, dos Estados, do Distrito Federal e dos Municípios a implementação de políticas públicas que visem a melhoria das condições habitacionais e de saneamento, o texto constitucional salvaguarda o direito à moradia digna. Além disso, cabe lembrar que o artigo $5^{\circ}$, 
inciso XI, da Constituição Federal, resguarda o domicílio de eventual violação, pois o caracteriza como asilo inviolável, salvo as hipóteses legalmente previstas na Constituição. Ainda acerca das referências à moradia incutidas no texto constitucional, Sarlet (2003) ressalta que a função social da propriedade, assim como a usucapião especial urbano e rural, vinculando, dentre outros quesitos, a declaração de domínio à utilização do imóvel para moradia, indicam a previsão constitucional deste direito.

Muito embora as previsões legais mencionadas, somente a partir da edição da Emenda Constitucional $\mathrm{n}^{\circ} 26$, em 2000, a moradia consagrou-se como direito fundamental social. A emenda conferiu uma nova redação ao caput do artigo $6^{\circ}$ da Constituição Federal, que passou a vigorar com o seguinte texto: "são direitos sociais a educação, a saúde, a alimentação, o trabalho, a moradia, o transporte, o lazer, a segurança, a previdência social, a proteção à maternidade e à infância, a assistência aos desamparados, na forma desta Constituição" (BRASIL, 1988). Desse modo, inseriu-se no ordenamento jurídico interno um direito anteriormente ratificado em tratados internacionais dos quais o Brasil é signatário.

O texto constitucional, a partir da referida emenda, passa a tutelar um direito fundamental à moradia, no entanto, trata-se de um direito abstrato, que carece de uma delimitação conceitual, bem como, de parâmetros identificadores do seu conteúdo. Nessa perspectiva, faz-se necessário buscar construções doutrinárias, jurídicas e normativas capazes de fornecer estes elementos terminológicos indispensáveis à compreensão da moradia como direito.

\section{A COMPLEXIDADE CONCEITUAL DO DIREITO FUNDAMENTAL SOCIAL À MORADIA}

Antes de se propor uma delimitação conceitual à moradia, mostra-se fundamental compreender que este direito é objeto de estudo de diversas áreas do conhecimento, para além das ciências jurídicas, assumindo assim uma pluralidade conceitual. Além disso, a língua portuguesa conta com uma infinidade de termos empregados com sinônimos da palavra moradia, tais como: domicílio, residência e habitação. 
Importa registrar que a moradia de modo algum se confunde com tais terminações. No que diz respeito ao domicílio, o Código Civil Brasileiro o define como o local onde o indivíduo estabelece sua residência com ânimo definitivo, onde alternativamente viva ou desenvolva atividades profissionais, ou ainda ausente qualquer destas estruturas o local onde se encontrar. Dessa forma, percebe-se que o domicílio consiste em um conceito legal imaterial, enquanto que a moradia se traduz em um direito concreto, demandando condições materiais ao seu exercício. A residência, por sua vez, trata-se do local onde o indivíduo se estabelece habitualmente, com a intenção de permanecer, ainda quando se afaste definitivamente (GOMES, 2007). Nesse sentido, a moradia diferencia-se da residência, tendo em vista que não se resume a uma estrutura física cuja permanência é habitual. Por fim, o vocábulo habitação corresponde à edificação destinada à morada (STEFANIAK, 2010). O direito civil admite que a habitação possa vir a ser considerada domicílio da pessoa natural, contudo, essa terminologia não conduz à melhor conceituação da moradia enquanto direito humano e fundamental. Resta evidente que essas terminações não contemplam a complexidade jurídica da moradia, e sequer podem ser utilizadas como expressões equivalentes a ela.

Não se mostra possível identificar no caput do artigo $6^{\circ}$ da Constituição Federal uma definição clara a respeito do conteúdo da moradia, o referido artigo traz em seu bojo uma proteção genérica, sem qualquer delimitação (FACCHINI, 2015a). Diante deste lapso constitucional, recorre-se às construções normativas internacionais a fim de definir a amplitude conteudística da moradia. Verifica-se que a Declaração de Istambul sobre Assentamentos Humanos - Habitat II, de 1996, consiste no documento mais completo no que se refere ao conteúdo do direito à moradia. A Agenda Habitat II definiu procedimentos hábeis para assegurar assentamentos humanos mais "seguros, saudáveis, habitáveis, equitativos, sustentáveis e produtivos" (HABITAT II, 1996, p.1).

Ainda na seara do direito internacional vale destacar os apontamentos feitos pelo Comitê dos Direitos Econômicos, Sociais e Culturais da Organização das Nações Unidas, Comentário Geral $n^{\circ} 4 . \mathrm{O}$ documento estabelece que o direito à moradia digna não deve ser objeto de uma interpretação restritiva, que o reduz a um local de abrigo provido meramente de um teto e quatro paredes, diferente disso, a moradia deve ser compreendida como um direito a viver (ONU, 1991). A partir deste registro, pode-se extrair uma definição concreta de moradia adequada, 
que para além de uma estrutura habitacional, contempla um ambiente que proporcione segurança, paz e dignidade ao indivíduo.

Além da contribuição conceitual, o Comentário $n^{0} 4$ elencou elementos jurídicos indispensáveis a consecução do direito à moradia, dentre os quais pode-se identificar:

a) Segurança jurídica para a posse, independentemente de sua natureza e origem.

b) Disponibilidade de infra-estrutura básica para a garantia da saúde, segurança, conforto e nutrição dos titulares do direito (acesso à água potável, energia para o preparo da alimentação, iluminação, saneamento básico, etc).

c) As despesas com a manutenção da moradia não podem comprometer a satisfação de outras necessidades básicas.

d) A moradia deve oferecer condições efetivas de habitabilidade, notadamente assegurando a segurança física aos seus ocupantes.

e) Acesso em condições razoáveis à moradia, especialmente para os portadores de deficiência.

f) Localização que permita o acesso ao emprego, serviços de saúde, educação e outras serviços sociais essenciais.

g) A moradia e o modo de sua construção devem respeitar e expressar a identidade e diversidade cultural da população (ONU, 1991, p.34).

Os elementos jurídicos elencados pelo Comitê no $\S 8^{\circ}$ do Comentário $\mathrm{n}^{\mathrm{o}} 4$ não constituem um rol taxativo, mas assumem um papel extremamente relevante no que diz respeito à materialização do direito à moradia. Essas diretrizes estabelecem parâmetros qualitativos à consecução da moradia digna, dentre os quais estão condições mínimas de habitação, higiene, segurança, dentre outros requisitos já apontados.

O Comitê dos Direitos Econômicos, Sociais e Culturais da Organização das Nações Unidas editou também o Comentário Geral $n^{\circ} 7$ que versa sobre os despejos forçados. O documento esclarece que os despejos não podem resultar em pessoas desabrigadas ou vulneráveis a violações de direitos humanos, dessa forma, o Poder Público está incumbido de assegurar moradia aos desalojados ilegalmente (ONU, 1997).

Logo, entende-se que o conteúdo do direito à moradia compreende a satisfação de condições mínimas que assegurem uma existência digna ao indivíduo. Nesse sentido, ao traçar parâmetros à consecução de um direito fundamental à moradia não se pode dissociá-lo do princípio da dignidade da pessoa humana, bem como, do conceito jurídico de mínimo existencial.

A incorporação do direito à moradia ao texto constitucional conferiu-lhe força normativa e segurança jurídica. Contudo, mostra-se inequívoco que mesmo antes da positivação 
lhe era assegurado gozo a partir do princípio da dignidade da pessoa humana resguardado pelo artigo $1^{\circ}$, inciso III, da Constituição. Nessa seara, cabe sinalar que:

[...] sempre haveria como reconhecer um direito fundamental à moradia como decorrência do princípio da dignidade da pessoa humana, já que este reclama, na sua dimensão positiva, a satisfação das necessidades existenciais básicas para uma vida com dignidade podendo servir até mesmo como fundamento direto e autônomo para o reconhecimento de direitos fundamentais não expressamente positivados [...]. (SARLET, 2008, p. 5).

Entende-se que o princípio da dignidade da pessoa humana estrutura o exercício dos direitos fundamentais previstos na Constituição brasileira, assim como resguarda a consecução daqueles ainda não positivados no texto constitucional. Na sua essência, busca atender necessidades indispensáveis à existência digna, proporcionando ao indivíduo condições para o desenvolvimento pleno. O direito de dispor de uma moradia decorre diretamente desse princípio, isso porque a carência de uma habitação adequada, que proteja física e psiquicamente o indivíduo, é incompatível com o conceito de dignidade da pessoa humana.

Sendo assim, o direito à moradia não se restringe a um espaço físico destinado a habitação, para além disso, compreende uma estrutura mínima que assegure qualidade de vida, condições adequadas de higiene e conforto, e que preserve a intimidade e privacidade do indivíduo (RANGEL; SILVA, 2009).

Nessa óptica, observa-se que o estudo deste direito fundamental social implica na compressão de sua relação intrínseca com a teoria de mínimo existencial. Inexiste no ordenamento jurídico brasileiro definição expressa do que seria o mínimo existencial, no que diz respeito à doutrina restam posicionamentos divergentes acerca do tema. A complexidade e abrangência jurídica dessa teoria dificultam uma delimitação do seu conteúdo. Nesse sentido Torres esclarece que:

Carece o mínimo existencial de conteúdo específico. Abrange qualquer direito, ainda
que originariamente não-fundamental (direito à saúde, à alimentação etc.),
considerado em sua dimensão essencial e inalienável. Não é mensurável, por envolver
mais os aspectos de qualidade que de quantidade, o que toma difícil estremá-lo, em
sua região periférica, do máximo de utilidade (maximum welfare,
Nutzenmaximierung), que é princípio ligado à ideia de justiça e de redistribuição da
riqueza social. Certamente esse mínimo existencial, se o quisermos determinar
precisamente, é uma incógnita muito variável. (TORRES, 1989, p. 29)

Em que pese a pluralidade de definições, a doutrina uniformiza-se ao interligar a teoria do mínimo existencial a prestações materiais que garantam condições mínimas de 
sobrevivência digna. Dentre essas condições, inegavelmente, encontra-se o direito de dispor de uma habitação que contemple as noções jurídicas de dignidade e liberdade.

Evidente que a moradia se trata de uma necessidade tão básica que sequer deveria despertar discussão quanto ao seu exercício. Não a garantir implica em deixar a população desprovida de meios essenciais à subsistência. A necessidade de estabelecer uma moradia decorre diretamente do direito à vida, de tal sorte que a ausência de condições materiais mínimas que viabilizem a sua fruição gera um dano irreparável na existência dos afetados (ALFONSIN, 2003). Justamente por ser a moradia um direito fundamental, indispensável à existência digna, tem-se assegurada a sua aplicabilidade imediata e eficácia plena, condições jurídicas que merecem exame.

Por força do artigo $5^{\circ}, \S 1^{\circ}$, da Constituição Federal, as normas definidoras de direitos fundamentais são dotadas de aplicabilidade imediata. Embora uma pequena parcela da doutrina entenda ser possível uma interpretação restritiva da referida norma, limitando a aplicabilidade imediata aos direitos individuais e coletivos previsto no artigo $5^{\circ}$ da Constituição, prepondera uma interpretação sistemática do texto constitucional. Dessa forma, a aplicabilidade imediata alcança todas as normas definidoras de direitos fundamentais, abrangendo o direito fundamental social à moradia positivado no artigo $6^{\circ}$ da Constituição Federal. Oportuno registrar que "a Constituição brasileira não estabeleceu distinção desta natureza entre os direitos de liberdade e os direitos sociais, encontrando-se todas as categorias de direitos fundamentais sujeitas, em princípio, ao mesmo regime jurídico" (SARLET, 2015, p. 268).

Nesse sentido, a previsão legal contida no artigo $5^{\circ}, \S 1^{\circ}$, da Constituição assegura aos direitos fundamentais a autoaplicabilidade, sendo assim, a inexistência de uma construção normativa por parte do poder legislativo não impede que tais direitos sejam acionáveis judicialmente. Cabe lembrar que a aplicabilidade direta não simboliza a irrelevância absoluta da legislação infraconstitucional, mas assegura que a ausência de possível regulamentação não obstaculize o exercício de um direito fundamental (SARLET; MARINONI; MITIDIERO, 2014).

A aplicabilidade imediata, em regra, atribui às normas de direitos fundamentais a presunção de uma eficácia plena, logo, a produção de efeitos jurídicos independente de 
regulamentação prévia por parte do poder legislativo. Desse modo, a ausência de lei não pode frustrar a aplicabilidade e eficácia dos direitos fundamentais.

No que diz respeito aos direitos de liberdade, de natureza predominantemente negativa, a aplicabilidade imediata e eficácia plena não despertam maiores questionamentos. No entanto, tratando-se dos direitos sociais, em razão da sua dimensão positiva, verificam-se divergências doutrinárias quanto ao reconhecimento da aplicabilidade direta e eficácia plena. Muito embora prevaleça o entendimento que as normas definidoras de direitos fundamentais gozem de aplicabilidade imediata e eficácia plena, ainda vigora a tese que os direitos sociais são dotados de um caráter programático, portanto, não dispõem de aplicabilidade direta e, consequentemente, não produzem efeitos imediatos.

Os direitos sociais, em especial a moradia, são também direitos fundamentais, o que importa dizer que estão sujeitos ao regime jurídico previsto no artigo $5^{\circ}, \S 1^{\circ}$, da Constituição, dessa forma, não se mostra possível classificá-los como normas meramente programáticas. Cabe aqui registrar que a norma programática é dotada de aplicabilidade mediata, ou seja, somente após uma interposição legislativa torna-se capaz de produzir efeitos jurídicos, despindo-se da chamada autoaplicabilidade (SARLET; MARINONI; MITIDIERO, 2014). A ausência de lei, com efeito, impede que esta norma alcance eficácia plena, retardando assim a produção de efeitos jurídicos.

Por derradeiro, constata-se que a moradia, mesmo que na sua condição de direito prestacional, não pode ser considerada norma de conteúdo meramente programático, uma vez que esta classificação vai de encontro com a previsão constitucional da aplicabilidade imediata das normas definidoras de direitos fundamentais.

\section{NECESSIDADES HABITACIONAIS NO BRASIL E AS CONTRADIÇÕES DA DESIGUALDADE SOCIAL: PERSPECTIVAS DE ENFRENTAMENTO A PARTIR DE UM DIREITO À CIDADE}


A previsão constitucional tardia do direito fundamental à moradia e a histórica resistência dos Estados com relação aos direitos sociais acarreta reflexos profundos nas condições de efetividade desses direitos. Evidentemente que não podem ser ignorados os investimentos demandados para tal concretização, mas, ao considerar-se que dentre os objetivos fundamentais da República Federativa do Brasil encontra-se a construção de uma sociedade justa, em que seja garantido o desenvolvimento nacional, erradicada a pobreza e reduzidas as desigualdades sociais e regionais (conforme artigo $3^{\circ}$, da Constituição Federal), não se pode permitir aos governos que se esquivem desses investimentos.

Mesmo porque é inegável que a desigualdade é fenômeno densamente enraizado na sociedade brasileira, apresentando-se de diversas formas: desigualdade de renda e de oportunidades, desigualdade racial e de gênero, desigualdade social presente nas disparidades de acesso à saúde, à educação, ao lazer e, no que toca diretamente ao presente estudo, de acesso à moradia (SCHWARCZ, 2019, p. 126).

Com relação à moradia, direito fundamental social sobre o qual se concentra o presente estudo, são muitas as falhas e contradições sistêmicas que podem ser destacadas, e que revelam esses problemas de raízes mais profundas e complexas, radicados na grande desigualdade social que assola o país, que também pode ser retratada, exemplificativamente, a partir da concentração de renda e terras nas mãos de poucos. ${ }^{3}$

Nesse sentido, é no mínimo curiosa a constatação de Moreira de "que nas listas que trazem os dez países com melhor sistema de educação, saúde, segurança, menor corrupção, melhor índice de desenvolvimento humano e vários outros indicadores sociais", frequentemente despontam os países nórdicos. Em contrapartida, ao se observarem as listas que indicam as pessoas mais ricas do mundo, raramente se encontra um indivíduo desses mesmos países. Nos rankings das maiores fortunas individuais, encontram-se sujeitos de vários outros países onde, "mesmo havendo um sistema democrático de votação, os donos das terras e dos meios de produção encontraram maneiras de tomar o controle de todo o processo distributivo e redistributivo de riqueza" (2019, p. 72-73).

\footnotetext{
${ }^{3}$ Considerando os limites e propósitos da presente pesquisa, não serão resgatados todos elementos determinantes dessa correlação. Contudo, foi tomado como base e, inclusive, recomenda-se para aprofundamento sobre esse ponto, a obra de SOUZA, 2018: "Uma história de desigualdade: a concentração de renda entre os ricos no Brasil, 1926-2013".
} 
A concentração de terras, aliás, é uma realidade que integra a formação histórica do território brasileiro, tendo se mantido relativamente estável ao longo dos anos. Segundo relatório da OXFAM, em dados elaborados a partir do Censo Agropecuário (2006) do Instituto Brasileiro de Geografia e Estatística (IBGE), no ano de 1985, o índice de Gini (indicador que mede a desigualdade, onde 0 corresponde à completa igualdade e 1 corresponde à completa desigualdade) nacional para a concentração da terra era de 0,856. Em 2006, o mesmo índice já havia alcançado 0,872 pontos (OXFAM, 2016, p. 6) - lembrando que 1 representa um cenário de absoluta desigualdade, o que equivaleria à concentração de toda a terra nas mãos de uma única pessoa.

Em relação à moradia, especificamente, em 2015 o Brasil apresentava um déficit habitacional estimado em 6,355 milhões de domicílios, de acordo com levantamento da Fundação João Pinheiro. Paradoxalmente, no mesmo ano, contabilizou-se a existência de 7,906 milhões de imóveis vagos (dos quais 6,893 milhões em condições de serem ocupados e 1,012 milhão em fase de construção ou reforma) (FUNDAÇÃO JOÃO PINHEIRO, 2018, p. 31 e p. 37). Isso significa que existem mais imóveis vagos no país do que o número de famílias sem moradia, desnudando um grave aspecto da desigualdade social.

De acordo com estudo realizado pela FGV, que apresenta dados relativos ao ano de 2017, o déficit habitacional brasileiro total já chegou a 7,77 milhões de unidades, cujos componentes são distribuídos em diversas categorias, tais como habitação precária (967.270 unidades); coabitação familiar (3.209.299 unidades); adensamento excessivo (303.711 unidades); e ônus excessivo com aluguel (3.289.948 unidades), que corresponde a 42,3\% do déficit habitacional (FGV, 2018, p. 11).

Como se pode perceber, ainda que o conceito de déficit habitacional designe uma "noção mais imediata e intuitiva de necessidade de construção de novas moradias para a solução de problemas sociais e específicos de habitação", existem outros indicadores da metodologia de cálculo das necessidades habitacionais (FUNDAÇÃO JOÃO PINHEIRO, 2018, p. 28).

Isso significa que o conceito de déficit habitacional utilizado como referência base para as pesquisas está ligado também às deficiências do estoque de moradias, englobando tanto "aquelas sem condições de serem habitadas em razão da precariedade das construções ou do desgaste da estrutura física", quanto "a necessidade de incremento do estoque, em função da 
coabitação familiar forçada [...], dos moradores de baixa renda com dificuldades de pagar aluguel nas áreas urbanas e dos que vivem em casas e apartamentos alugados com grande densidade". Podem ser incluídas ainda nessa rubrica as moradias em imóveis e locais com fins não residenciais (FUNDAÇÃO JOÃO PINHEIRO, 2018, p. 31 e p. 37).

Nos termos postos por Nassar, o cálculo do déficit habitacional compreende um amplo conceito, que abrange tanto a necessidade de construção de novas moradias para a solução de problemas sociais detectados em determinado momento e contexto, quanto a questão da inadequação de domicílios, que demanda, por exemplo, ações e políticas públicas voltadas à melhoria dos domicílios existentes (2014, p. 3$)$.

Outro aspecto que merece destaque, notadamente em vista dos objetivos propostos no sentido de averiguar as intersecções entre desigualdade social e os problemas de efetivação do direito à moradia, é o enorme crescimento da participação do componente de ônus excessivo com aluguel ao longo dos anos: "entre 2007 e 2017, a participação do componente ônus excessivo com aluguel passou de 24,2\% para 42,3\%, passando a atingir 1,5 milhão de domicílios a mais" (FGV, 2018, p. 11). Neste conceito compreendem-se as famílias urbanas cuja renda familiar é de até três salários mínimos, e que despendem mais de $30 \%$ de sua renda com o pagamento de aluguel.

Trata-se de um elemento difícil de mensurar, considerando-se que "o ônus excessivo com o pagamento de aluguel pode ser tornar um componente maior ou menor do déficit em razão da dinâmica da renda das famílias" e, por isso, não está livre de controvérsias. Por um lado, é possível cogitar que uma economia aquecida poderia gerar a ampliação dos níveis de renda e, consequentemente, reduzir esse ônus sem que houvesse, efetivamente, nem o crescimento do estoque de moradias, nem a redução dos preços dos aluguéis. Ainda, também seria necessário refletir sobre o fato de que, famílias que moram nas periferias e subúrbios mais distantes o façam como alternativa em prol de aluguéis menos onerosos, mas que, em contrapartida, suportam o ônus dessa distância com gastos em transporte e horas de deslocamento aos locais de trabalho, por exemplo. Não deveria, portanto, tal custo implícito integrar o cálculo do déficit habitacional? (FGV, 2018, p. 13).

De todo modo, ainda que para fins de cálculo esse dado possa trazer complicações, tratase de uma realidade que não pode ser afastada do debate, pois revela justamente a densidade do 
problema em questão. O direito à moradia, como se percebe, é um direito extremamente complexo, cuja efetivação demanda uma série das ações e políticas que vão muito além da "construção de casas".

Nesse sentido, a própria ideia de um direito à cidade precisa ser debatida, já que se trata de um espaço socialmente construído e fruído, não de um amontoado de residências. As cidades não são aglomerados de casas, mas verdadeiras instituições. Na definição proposta por Lopes, "as cidades são [...] um espaço humano, que se opõe e se distingue do espaço natural, meramente geográfico" (p. 2006, p. 59).

Como espaços artificiais e socialmente construídos, as cidades produzem e reproduzem as desigualdades que permeiam as relações humanas, sendo este espaço, justamente, decisivo para o estabelecimento das diferenças entre ricos e pobres. No campo há um predomínio maior da força da natureza sobre a vontade humana, partilha-se a penúria e a abundância, já que a propriedade não é um problema em especial, pois aquilo que realmente importa (o rebanho, a terra de cultivo) é possuído em comum pelas famílias. Por sua vez, nas cidades se estabelece um ritmo de acumulação que pressupõe a privação de alguns. Busca-se um controle da natureza e um ritmo de exploração por quem detém determinadas propriedades que é gerada uma acumulação desigual e desproporcional. Assim, a cidade produz, "como nunca antes, a distinção entre ricos e pobres. O nível de vida muda e varia conforme a classe social”, que é criada e acentuada a partir da cidade (LOPES, 2006, p. 60-61).

Por isso este trabalho assumiu a premissa de que os temas desigualdade social e direito à moradia estão umbilicalmente relacionados, conformando-se um contexto de apropriação da moradia pelo capital que gera exclusão e conflito, reformulando-se as próprias cidades e modos de vida urbana para o atendimento desses interesses econômicos pontuais.

Nas cidades de hoje impera uma "mercantilização da moradia" e um "uso crescente da habitação como um ativo integrado a um mercado financeiro globalizado" que "afetou profundamente o exercício do direito à moradia adequada pelo mundo". Na pertinente crítica de Rolnik, "a crença de que os mercados poderiam regular a alocação da moradia, combinada com o desenvolvimento de produtos financeiros experimentais" para tanto, "levou ao abandono de políticas públicas em que a habitação é considerada um bem social, parte dos bens comuns 
que uma sociedade concorda em compartilhar ou prover para aqueles com menos recursos" (2015, p. 32).

Prova disso são os inúmeros episódios ao redor do mundo em que o direito à moradia das famílias que perderam suas casas foi preterido em detrimento da recuperação do sistema financeiro ameaçado pela crise gerada a partir de bolhas imobiliárias. Tomando como o exemplo um dos cenários mais conhecidos, em 2007, um ano desastroso para os mercados financeiros, os bônus dos financistas em Wall Street chegaram a 33,2 bilhões de dólares. "O Federal Reserve (FED) e o Banco Central Europeu injetaram bilhões de dólares em créditos a curto prazo no sistema financeiro para garantir sua estabilidade [...].” Em contrapartida, cerca de 2 a 3 milhões de pessoas perdiam suas casas por execução de hipotecas, e vários bairros e comunidades norte-americanas tornaram-se praticamente "cidades-fantasma", arruinados pelas práticas de crédito predatórias das instituições financeiras e com o aval dos governos (HARVEY, 2014, p. 63-64).

Trata-se de uma realidade que se confirma também a respeito do Brasil. $\mathrm{O}$ alerta feito por Harvey de que "o direito à cidade como hoje existe [...] encontra-se muito mais estreitamente confinado, na maior parte dos casos, nas mãos de uma pequena elite política e econômica com condições de moldar a cidade cada vez mais segundo suas necessidades particulares" (2014, p. 64) e desejos pode ser visualizado em inúmeras contradições que a desigualdade social brasileira tem acentuado.

Enquanto tantos milhões de brasileiros estão sem acesso à moradia adequada e outros tantos milhões de famílias de baixa renda comprometem mais de $30 \%$ de seus recursos (de acordo com dados expostos anteriormente) com o pagamento de alugueis, condomínios luxuosos e espaços cujos acessos são cada vez mais exclusivos não param de tomar as cidades, e os gastos com auxílio-moradia para magistrados que têm casa própria alcançam cifras milionárias. $^{4}$

\footnotetext{
${ }^{4}$ Os estudos e dados são variados. Toma-se como referência, aqui, a pesquisa "Quem somos - a magistratura que queremos", divulgada pela Associação dos Magistrados do Brasil (AMB) e noticiada pelo Jornal Folha de São Paulo, onde consta que 70,1\% dos juízes primeira instância e 93,2\% magistrados de segunda instância declararam ser proprietários de imóveis, sendo que o auxílio-moradia foi universalizado em 2014 por uma decisão liminar do Ministro Luiz Fux. Disponível em: https://www1.folha.uol.com.br/poder/2019/02/em-ano-com-auxilio-moradiauniversal-mais-de-70-dos-juizes-tinham-casa-propria.shtml. Acesso em: 27 Abr. 2019.
} 
É o que Rosanvallon de "paradoxo de Bossuet”, do qual se utiliza para descrever o modo de vida atual, em que um rechaço global sobre uma determinada forma de sociedade coexiste com a aceitação dos mecanismos que a produzem. Isso é, condenam-se as desigualdades de fato enquanto são reconhecidos implicitamente como legítimos os mecanismos que produzem toda essa desigualdade. Essa situação paradoxal, segundo o autor, é a base da esquizofrenia contemporânea, em que se lamenta em geral sobre aquilo que se aceita em particular (2012, p. 16).

São apenas exemplos e teses pontuais dentre tantos que poderiam ser explorados, mas que endossam o argumento apresentado de que, para a economia política dominante a habitação é um meio de acesso à riqueza, e "a casa transforma-se de bem de uso em capital fixo - cujo valor é a expectativa de gerar mais-valor no futuro, o que depende do aumento do preço dos imóveis no mercado" (ROLNIK, 2015, p. 33).

Desse modo, uma adequada prestação do direito à moradia, como antecipado, exigirá políticas públicas que abarquem toda a complexa realidade social das cidades brasileiras, além de uma profunda revisão paradigmática sobre o significado desse importante direito para a realização da dignidade humana, para a vida compartilhada nas cidades e para a consecução ampla dos objetivos constitucionais do Estado brasileiro.

\section{CONCLUSÃO}

A presente pesquisa partiu do seguinte questionamento: se e como as desigualdades sociais agravam o déficit habitacional e quais as perspectivas de enfrentamento a esse problema? Visando responder ao problema, três tópicos foram enfrentados: (i) o de retomada histórica dos direitos sociais e a consolidação dos instrumentos jurídicos protetivos do direito à moradia; (ii) o de investigação e delimitação conceitual; (iii) o de apontamento e avaliação das necessidades habitacionais no Brasil e as relações com os índices crescentes de desigualdade social. 
Relativamente ao primeiro ponto, trabalhou-se com diversas fases e documentos ao longo de séculos que foram moldando, paulatinamente, os instrumentos jurídicos de reconhecimento e proteção de um direito fundamental social à moradia. Destaca-se, contudo, o forte caráter político presente na defesa da moradia enquanto direito fundamental, já que direitos dessa natureza demandam do Estado prestações e investimentos diretos. Justifica-se, assim, o conjunto de questionamentos ligados ao papel dos Estados na efetivação de um direito à moradia e, até mesmo, as resistências com relação a sua constitucionalização.

Com relação ao segundo objetivo traçado como meio para responder ao problema, identificou-se que o direito à moradia não se restringe ao espaço físico destinado à habitação, compreendendo muito mais do que disso, pois vincula-se diretamente à noção de dignidade da pessoa e da existência humana. Ademais, considerando-se os pressupostos constitucionais para aplicação dos direitos fundamentais, concluiu-se que o direito à moradia é dotado de aplicabilidade imediata e, não obstante o seu traço programático dado o caráter de direito social, não pode ser reduzido a essa condição como pretexto para a sua não efetivação.

Por fim, acerca das necessidades habitacionais e correlações com a desigualdade social, identificou-se que uma adequada prestação do direito à moradia exigirá políticas públicas mais amplas, pois, para além da construção de novas moradias, há outros fatores que concorrem para o déficit habitacional, como inadequação das moradias, coabitação forçada, entre outros elementos abordados no texto. Dentre esses outros fatores, destacou-se o chamado "ônus excessivo com aluguel", que explicita, de forma mais direta, as dificuldades que a desigualdade de renda, sobretudo, adiciona à prestação adequada do direito à moradia, porquanto implica um comprometimento considerável de renda das famílias com essa despesa.

Nesse sentido, considerando-se o aspecto da mercantilização e financeirização da moradia, sustenta-se que serão necessárias ações e políticas mais abrangentes para enfrentar essa realidade desigual, além de um repensar sobre as próprias cidades brasileiras, sobre o significado de moradia para a realização da dignidade humana, sobre a vida compartilhada nas cidades e sobre a consecução dos objetivos do Estado brasileiro. 


\section{REFERÊNCIAS}

ALFONSIN, Jacques Távola. $O$ acesso à terra como conteúdo de direitos humanos fundamentais à alimentação e moradia. Porto Alegre: Fabris, 2003.

ANDRADE, José Carlos Vieira de. Os Direitos Fundamentais na Constituição Portuguesa de 1976. 4. ed. Coimbra: Almedina. 2009.

BRASIL. Constituição da República de Federativa do Brasil (1988). Disponível em: http://www.planalto.gov.br. Acesso em: 04/02/2019.

BRASIL. Código Civil (2002). Disponível em: http://www.planalto.gov.br. Acesso em: 04/02/2019.

BRASIL. Direito à moradia adequada. Brasília: Coordenação Geral de Educação em SDH/PR, Direitos Humanos, Secretaria Nacional de Promoção e Defesa dos Direitos Humanos, 2013. Disponível em: http://www.sdh.gov.br. Acesso em: 12/07/2017.

FACCHINI, Nicole Mazzoleni. Direito fundamental à moradia: sua eficácia à luz do direito internacional, do direito constitucional e das políticas públicas. Passo Fundo: Projeto Passo Fundo, 2015a.

FACCHINI, Nicole Mazzoleni. Direitos fundamentais e proteção da moradia: harmonização de conflitos à luz do princípio da proporcionalidade. Passo Fundo: Projeto Passo Fundo, 2015b.

FGV. Análise das necessidades habitacionais e suas tendências para os próximos dez anos. Relatório técnico final. $2^{\mathrm{a}}$ versão. 2018. Disponível em: https://www.abrainc.org.br/wpcontent/uploads/2018/10/ANEHAB-Estudo-completo.pdf. Acesso em: 06 Abr. 2019.

FUNDAÇÃO JOÃO PINHEIRO. Déficit habitacional no Brasil 2015. Belo Horizonte: FJP, 2018.

GOMES, Orlando. Introdução ao direito civil. 19. ed., V.I. Rio de Janeiro: Forense, 2007.

HARVEY, David. Cidades rebeldes: do direito à cidade à revolução urbana. São Paulo: Martins Fontes, 2014.

LEDUR, José Felipe. Direitos Fundamentais sociais: efetivação no âmbito da democracia participativa. Porto Alegre: Livraria do Advogado Editora, 2009.

LOPES, José Reinaldo de Lima. Direitos sociais: teoria e prática. São Paulo: Método, 2006.

NASSAR, Paulo André. Direito à moradia: o que os juristas têm a ver com isso? Disponível em: https://pauloandrenassar.files.wordpress.com/2014/11/nassar-direito-a-moradia-sbdp.pdf. Acesso em: 06 Abr. 2019.

MOREIRA, Eduardo. Desigualdade \& caminhos para uma sociedade mais justa. 2. ed. Rio de Janeiro: Civilização Brasileira, 2019. 
NOGUEIRA, Italo. Jornal Folha de São Paulo. Em ano como auxílio-moradia universal, mais de $70 \%$ dos juízes tinham casa própria. Disponível em: https://www1.folha.uol.com.br. Acesso em: 27 Abr. 2019.

NOVAIS, Jorge Reis. Direitos Sociais: teoria jurídica dos direitos sociais enquanto direitos fundamentais. Coimbra: Coimbra, 2010.

ONU. Comitê dos Direitos Econômicos, Sociais e Culturais. Comentário Geral no 4 (1991). Disponível em: http://www.sdh.gov.br/assuntos/bibliotecavirtual/promocao-edefesa/publicacoes-2013/pdfs/direito-a-moradia-adequada. Acesso em: 30/06/2017.

ONU. Comitê dos Direitos Econômicos, Sociais e Culturais. Comentário Geral $\mathrm{n}^{\circ} 7$ (1997). Disponível em: http://pfdc.pgr.mpf.mp.br/atuacao-e-conteudos-de-apoio/legislacao/reformaagraria/ComentarioGeral7_DESC. Acesso em: 30/06/2017.

ONU. Declaração de Istambul sobre Assentamentos Humanos (1996). Disponível em: http://pfdc.pgr.mpf.mp.br/atuacao-e-conteudos-de-apoio/legislacao/moradiaadequada/declaracoes/declaracao-de-istambul-sobre-assentamentos-humanos. Acesso em: 07/01/2017.

ONU. Declaração Universal dos Direitos Humanos (1948). Disponível em: http://unesdoc.unesco.org/images/0013/001394/139423por.pdf. Acesso em: 09/07/2017.

ONU. Pacto Internacional dos Direitos Econômicos Sociais e Culturais (1966). Disponível em: http://www.planalto.gov.br/ccivil_03/decreto/1990-1994/d0591.htm. Acesso em: 29/06/2017.

OXFAM. Terrenos da desigualdade: terra, agricultura e desigualdades no Brasil rural (2016). Disponível em: https://www.oxfam.org.br/publicacoes/terrenos-da-desigualdade-terraagricultura-e-desigualdade-no-brasil-rural. Acesso em: 06 Abr. 2019.

PERES LUÑO, Antonio Enrique. Derechos humanos, estado de derecho y constituición. 10. ed. Madrid: Tecnos, 2010.

PIOVESAN, Flávia. Direitos humanos e o direito internacional. 13.ed. São Paulo: Saraiva, 2012.

RANGEL, Helano Márcio Vieira; SILVA, Jacilene Vieira. O direito a moradia como mínimo existencial, e sua efetivação à luz do Estatuto da Cidade. Revista Veredas do Direito, Belo Horizonte. V.2, n.12, p.57 - 78. Julho-dezembro, 2009.

ROLNIK, Raquel. Guerra dos lugares: a colonização da terra e da moradia na era das finanças. São Paulo: Boitempo, 2015.

SARLET, Ingo Wolfgang. Eficácia dos Direitos Fundamentais: uma teoria dos direitos fundamentais na perspectiva constitucional. 12. ed. Porto Alegre: Livraria do Advogado, 2015.

SARLET, Ingo Wolfgang. O Direito Fundamental à Moradia aos Vinte Anos da Constituição Federal de 1988: Notas a Respeito da Evolução em Matéria Jurisprudencial, com Destaque para a Atuação do Supremo Tribunal Federal. Revista Brasileira de Estudos Constitucionais - 
RBEC, Ano 2, n. 8, outubro/dezembro de 2008, p. 55-92. Disponível em: http://www.egov.ufsc.br/portal/sites/default/files/anexos/32734-40344-1-PB.pdf. Acesso: 20/06/2017.

SARLET, Ingo Wolfgang; MARINONI, Luiz Guilherme; MITIDIERO, Daniel. Curso de Direito Constitucional. ed. 3. São Paulo: Revista dos Tribunais, 2014.

SCHWARCZ, Lilia Moritz. Sobre o autoritarismo brasileiro. São Paulo: Companhia das Letras, 2019.

SOUZA, Pedro H. G. Ferreira de. Uma história de desigualdade: a concentração de renda entre os ricos no Brasil, 1926-2013. São Paulo: Hucitec - Anpocs, 2018.

STEFANIAK, João Luiz. A efetividade do direito humano e fundamental à moradia. Revista Direitos Fundamentais e Democracia. V. 8, n. 8, (jul./dez. 2010), p. 237-256. Disponível em: http://revistaeletronicardfd.unibrasil.com.br/index.php/rdfd/article/view/24. Acesso em: 10/07/2017.

ROSANVALLON, Pierre. La sociedad de los iguales. Traducción de Maria Pons. Barcelona: RBA Libros S.A., 2012.

TORRES, Ricardo Lobo. O mínimo existencial e os direitos fundamentais. Disponível em: http://bibliotecadigital.fgv.br/ojs/index.php/rda/article/viewFile/46113/44271. Acesso em: 08/07/2017.

UNIÃO EUROPEIA. Carta dos direitos fundamentais da união europeia (2000). Disponível em:< http://www.europarl.europa.eu/charter/pdf/text_pt.pdf>. Acesso em: 10/03/2019.

Data de Submissão: 30/07/2019

Data de Aceite: 16/04/2020 